Научная статья

УДК 338.984

DOI: $10.18101 / 2304-4446-2021-2-24-32$

\title{
ОЦЕНКА ОБОСНОВАННОСТИ ПЕРЕПЛАНИРОВАНИЯ КЛЮЧЕВЫХ ПРОИЗВОДСТВЕННЫХ ПРОЦЕССОВ ОРГАНИЗАЦИЙ В СФЕРЕ ЖИЛИЩНО-КОММУНАЛЬНОГО ХОЗЯЙСТВА
}

\author{
(C) Мавлютов Рамиль Ростемович \\ кандидат экономических наук, доцент, \\ Волгоградский государственный технический университет \\ Россия, 400005, г. Волгоград, пр-т им. Ленина, 28 \\ ramil-2002@mail.ru
}

\begin{abstract}
Аннотация. Для отечественных организаций сферы жилищно-коммунального хозяйства (ЖКХ) в современных условиях первостепенной проблемой становится внедрение передовых технологических решений. В контексте провозглашенной Россией цели широкого внедрения передовых цифровых и инженерных решений в городской и коммунальной инфраструктуре, реализуемой в рамках национального проекта «Жилье и городская среда» и национальной программы «Цифровая экономика», для страны формируется новая парадигма - включиться в общемировой процесс новой технологической революции. Этого невозможно достичь без кардинального перепланирования ключевых производственных процессов организаций сферы ЖКХ. Эта процедура рассматривается нами как «реинжиниринг производственных процессов». Представлен подход к оценке обоснованности реинжиниринга производственных процессов организации сферы ЖКХ, реализуемого с привлечением инжиниринговой компании. Приведены выгоды, обусловленные привлечением инжиниринговой компании. Предложенный подход позволяет рассчитать реинжиниринговый консоль, что дает возможность принять аргументированное решение о реализации проекта реинжиниринга как организацией, так и инжиниринговой компанией. Данное исследование может быть востребовано как потенциальными участниками процесса, так и учеными, которые проводят изыскания в данной области.

Ключевые слова: жилищно-коммунальное хозяйство, организация, технологическая революция, производственный процесс, реинжиниринг, оценка, жилищный фонд, коммунальная инфраструктура, чистый дисконтированный доход, риск
\end{abstract}

\section{Для цитирования}

Мавлютов Р. Р. Оценка обоснованности перепланирования ключевых производственных процессов организаций в сфере жилищно-коммунального хозяйства // Вестник Бурятского государственного университета. Экономика и менеджмент. 2021. № 2. С. 24-32.

С начала 2010-х гг. структура и специфика современного производства претерпевает кардинальные изменения под влиянием интенсивного развития и последующего внедрения передовых технологических решений, роста наукоемкости продукции и услуг. Характер трансформации столь значим, что трактуется как новая технологическая революция. В связи с этим производственная деятельность организаций, особенно традиционных отраслей, формирует повышенный спрос на услуги инжиниринговых компаний. Особое место здесь принадле- 
P. Р. Мавлютов. Оценка обоснованности перепланирования ключевых производственных процессов организаций в сфере жилищно-коммунального хозяйства

жит организациям сферы ЖКХ, которые формируют для населения жизнеобеспечивающую среду. Под инжиниринговой компанией понимается эксперт, который, обладая профессиональными компетенциями в определенной области, оказывает посреднические услуги в рамках интеграции и координации работ в рамках внедрения новых технологических решений [5, с. 65]. Эти услуги охватывают все этапы технологической цепочки производства продукции, оказания услуг.

Масштабные изменения, которые сейчас претерпевает мировая экономика, именуются новой технологической революцией. В ее основе находится переход от производства стандартизированной продукции к клиентоориентированному адаптируемому производству [6, с. 10]. В России сфера ЖКХ традиционно характеризуется высоким уровнем ресурсоемкости и энергоемкости [9, с. 845]. Вследствие чего в долгосрочной перспективе ключевым вызовом для отрасли выступает повышение эффективности контроля за сроками и ходом оказания услуг. Здесь формируется необходимость разрешения комплекса вопросов технологического и организационного характера, что должно стать задачей инжиниринговой компании. Тем самым возможно достичь роста конкурентоспособности организации ЖКХ. С нашей точки зрения, внедрение цифровых технологий в сфере ЖКХ приводит к комплексной экономии ресурсов на всех стадиях жизненного цикла объектов жилищного фонда и коммунальной инфраструктуры в рамках их эксплуатации. Вместе с тем российские организации ЖКХ проявляют низкую мотивацию к применению инжиниринговых услуг по причине низкой стабильности ведения бизнеса и малой для них очевидности достижения эффекта [8, с. 103]. То есть имеет место несоответствие высоких издержек по привлечению эксперта-посредника ожидаемой отдаче.

Понятие «реинжиниринг» было введено в научный оборот в начале 1990-х гг. В области программного обеспечения первопроходцами были Chikofsky Е. и Cross J. [2], в сфере бизнес-процессов - Henry J. Johansson, Patrick McHugh, A. John Pendlebury, William A. Wheeler [4], Richard C. Dorf [3]. В 1994 г. увидело свет исследование M. Betts, T. Wood-Harper [1], в рамках которого речь шла об реинжиниринге в строительстве. Оперяясь на означенные фундаментальные исследования, мы в рамках настоящего исследования под реинжинирингом производственных процессов понимаем радикальное перепланирование ключевых производственных процессов в целях качественного улучшения их выполнения с точки зрения затрат, качества обслуживания и скорости. В организациях ЖКХ инструментами реинжиниринга производственных процессов должно стать применение информационных моделей объектов жилищного фонда и коммунальной инфраструктуры, реализуемых на основе ВIM-технологий. Посреднические услуги в этом вопросе оказывают инжиниринговые компании, специализирующиеся на внедрении реинжиниринга на практике. Оговоримся, что в мировой практике такого рода услуги оказывают реинжиниринговые компании [10]. Но в силу того, что российский рынок такого рода услуг находится на стадии становления, в большинстве своем они оказываются инжиниринговыми компаниями, которые еще не обрели узкой специализации. Однако в России реинжинирингом занимаются компании, которые можно разделить на три группы. Во-первых, это консалтинговые компании, оказывающие, прежде всего, аудиторские услуги. Вовторых, проектные компании, которые разрабатывают проект оптимального бизнеса, но не оказывают услуг по внедрению реинжиниринга. В-третьих, инжини- 
ринговые компании, осуществляющие практическое внедрение реинжиниринга. Задача компаний этой группы состоит в реорганизации системы управления, ее оптимизации [7, с. 19-21].

Объектом исследования выступают реинжиниринг производственных процессов организации сферы ЖКХ, а предметом исследования является оценка целесообразности реинжиниринга производственных процессов организации сферы ЖКХ. В рамках данной статьи с целью формализации процедуры оценки целесообразности реинжиниринга производственных процессов организации сферы ЖКХ, реализуемого с привлечением инжиниринговой компании, поставлены следующие задачи: определение основных выгод использования организацией сферы ЖКХ услуг инжиниринговой компании, установление степени воздействия на величину прибыли организации сферы ЖКХ выгод - как кумулятивно, так и по отдельности.

В условиях экономики России, относящейся к числу транзитивных, реинжиниринг связывается с комплексом эффектов, которые обеспечиваются переходом к управлению жилищным фондом и объектами коммунальной инфраструктуры на основе цифровых моделей. Эти эффекты в условиях привлечения инжиниринговой компании идентифицируются и подлежат количественному измерению.

Решение поставленных в исследовании задач основывается на применении следующих методов: анализ, синтез, классификация, моделирование. Количественное определение величины прибыли, обеспечиваемой привлечением организацией ЖКХ инжиниринговой компании, основано на применении показателя чистого дисконтированного дохода (ЧДД) - (Net present value, NPV), который исчисляется по общеизвестной формуле:

$$
\text { ЧДД }=\sum_{i=1}^{n} \frac{N C F_{i}}{(1+I)^{i}}-\sum_{i=1}^{n} \frac{I n v_{i}}{(1+I)^{i}},
$$

где $N C F_{i}$ - чистый денежный поток $i$-го периода инвестиционного проекта,

$\operatorname{Inv} v_{i}$ - инвестиции, реализованные на $i$-м периоде инвестиционного проекта,

$I$ - стоимость капитала, привлеченного для реализации инвестиционного проекта,

$n$ - период реализации инвестиционного проекта (горизонт расчета).

Ряд исследователей сходятся во мнении, что привлечение инжиниринговой компании обеспечивает заказчику комплекс преимуществ. К их числу относится: сокращение сроков реализации проекта; применение передового опыта реализации технологических решений; повышение эффективности организации производственного процесса; снижение уровня производственных рисков. Для того чтобы количественно определить величину прибыли, обеспечиваемой привлечением организацией ЖКХ инжиниринговой компании, предлагаем использовать понятие реинжиниринговый консоль (англ. consol, сокр. от consolidated annuity). Формирование реинжинирингового консоля происходит по ряду причин: наличие у инжиниринговой компании уникальных компетенций; системный подход в организации процесса; возможность обоснованного выбора поставщиков и подрядчиков с высокой степенью выполнения договорных условий. Суммарный эффект приведенных причин обусловливает положительное влияние на результа- 
P. Р. Мавлютов. Оценка обоснованности перепланирования ключевых производственных процессов организаций в сфере жилищно-коммунального хозяйства

тивность реализуемого проекта в части обеспечения организации производственных процессов.

Как правило, реализация проектов реинжиниринга занимает значительный период времени, который может достигать нескольких лет, в связи с чем возникает необходимость учета фактора времени. В целях оценки обоснованности проекта прибегают к показателю чистого дисконтированного дохода (NPV). Он представляет собой наиболее распространенный показатель, который учитывает фактор времени. Учитывая введенную нами трактовку реинжинирингового консоля (далее REC), специфики его формирования, в рамках данного исследования мы предлагаем произвести расчет REC как чистый дисконтированный доход проекта, который предусматривает применение услуг инжиниринговой компании (далее - ЧДДREC), за минусом чистого дисконтированного дохода проекта без привлечения инжиниринговой компании (далее - ЧДД0).

$$
R E C=\text { ЧДД }{ }_{R E C}-\text { ЧДД, }
$$

Для последующего анализа формулу (1) представим в следующем виде:

$$
\text { ЧДД }=\sum_{i=1}^{n} \frac{\left(1-I T_{i}\right)\left(P \times_{i} Q_{i}-V C_{i}-F C_{i}-M P_{i}-O E_{i}\right)}{(1+I)^{i}}-\sum_{i=1}^{n} \frac{\operatorname{Inv} v_{i}}{(1+I)^{i}} \text {, }
$$

где $I T_{i}-$ ставка налога на прибыль организаций (принятая в долях единицы),

$P_{i}$ - стоимость единицы продукции (например, рубли за 1 Гкал тепловой энергии, 1 кВТ·ч, техническое обслуживание 1 м $^{2}$ общей площади многоквартирного дома и т. д.),

$Q_{i}$ - объем продаж,

$V C_{i}$ - переменные издержки,

$F C_{i}$ - постоянные издержки,

$M P_{i}$ - долговая нагрузка в виде процентных выплат по обслуживанию кредита (в случае ее наличия),

$O E_{i}$ - прочие расходы, относимые на финансовый результат организации.

Изучение практики функционирования реинжиниринговых компаний за пределами России обосновало формулировку выгод, которые обеспечиваются их привлечением, в частности для обеспечения перехода к управлению жилищным фондом и объектами коммунальной инфраструктуры на основе цифровых моделей:

1. Сокращение срока реализации проекта.

2. Частичное нивелирование рисков.

3. Разработка реинжиниринговых решений.

4. Высокий уровень деловой репутации инжиниринговой компании, транслируемый организации-заказчику.

Необходимо детально рассмотреть влияние, оказываемое привлечением инжиниринговой компании на составляющие ЧДД.

1. Сокращение срока реализации проекта. Мировой опыт применения информационных моделей при эксплуатации объектов жилищного фонда и коммунальной инфраструктуры свидетельствует, что сроки реализации проекта сокращаются [10]. Поэтому $n_{R E C}<n_{0}$. При прочих равных условиях проект с меньшим периодом реализации имеет чистый дисконтированный доход больше. В данном 
случае формируется часть реинжинирингового консоля, обусловленного ростом интенсификации реализации проекта.

2. Частичное нивелирование рисков. Налаживанию производственных процессов в организации сферы ЖКХ свойственен целый комплекс рисков. При этом они непосредственно влияют на составные элементы при расчете величины ЧДД проекта. Произведем классификацию означенных рисков, учитываемых при определении ЧДД. Общепризнанно разделение рисков в зависимости от источника происхождения на внутренние и внешние.

К числу рисков внутреннего порядка нами отнесены следующие риски.

Риск несоответствия квалификачионного уровня работников тем производственным процессам, к реализации которых он привлечен. Следствием его выступают перманентный рост постоянных и переменных издержек по причине принятия неверных решений, а также снижение уровня качества продукции, услуг. Обозначим его как $R_{s t}$.

Производственный риск, обусловленный технологическими процессами. Этот риск обусловлен технологическими процессами, в ходе реализации которых возможен выход из строя производственного оборудования из-за несвоевременного его обслуживания, ненадлежащей эксплуатации. Вследствие этого растут постоянные издержки, прочие расходы. Обозначим этот риск как $R_{t}$.

Риск денежного рынка. Его генезис состоит в удорожании внешнего финансирования по причине колебания стоимости денег, инфляции, изменения учетной ставки и т. д. В итоге организация сталкивается с ростом постоянных и переменных издержек, долговой нагрузки, прочих расходов. Обозначим этот риск как $R_{m}$.

К числу рисков внешнего происхождения нами отнесены следующие риски.

Риск несоблюдения сроков поставки материалов. Данный риск вызван отсутствием возможности закупки необходимых материально-технических ценностей по разного рода причинам: логистические проблемы, одностороннее изменение поставщиком договорных условий, мошенничество. В результате - рост постоянных издержек и прочих расходов. Обозначим этот риск как $R_{s}$.

Конкурентный риск. Он происходит от вероятности выхода на рынок конкурентных предложений, которые в большей мере соответствуют запросам потребителей, из-за использования нерыночных форм борьбы за сбыт (оказание давления на поставщиков и потребителей, их дезинформирование, распространение ложной информации о продукции и т. д.). В результате падает объем продаж. Обозначим этот риск как $R_{r}$.

Риск наступления форс-мажора. Его невозможно предусмотреть ввиду непредвиденного характера появления, поэтому его отнесем к прочим расходам. Обозначим данный риск как $R_{f}$.

Риск ухудшения рыночной конъюнктуры. Этот риск происходит от замедленного, несвоевременного внедрения в производство инновационных решений, неполной информации о конкурирующих компаниях. Вследствие этого замедляется сбыт продукции, снижается отпускная цена. Обозначим этот риск как $R_{c}$.

Риск роста стоимости капитала. Он неминуемо сопровождает любой проект, поэтому подлежит обязательному учету. Обозначим его $R_{I}$.

Таким образом, с учетом (3) кумулятивное влияние на величину ЧДД описанных рисков можно определить с помощью формулы: 
P. Р. Мавлютов. Оценка обоснованности перепланирования ключевых производственных процессов организаций в сфере жилищно-коммунального хозяйства

$$
\begin{gathered}
\text { чДД }=\sum_{i=1}^{n}\left(1-I T_{i}\right) \times\left(\frac{R_{r} \times R_{c} \times P_{i} \times Q_{i}-R_{s t} \times R_{m} \times V C_{i}}{\left(1+R_{I} \times I\right)^{i}}-\right. \\
\left.-\frac{R_{s t} \times R_{t} \times R_{m} \times R_{s} \times F C_{i}+R_{m} \times M P_{i}+R_{t} \times R_{m} \times R_{s} \times R_{f} \times O E_{i}}{\left(1+R_{I} \times I\right)^{i}}\right)- \\
-\sum_{i=1}^{n} \frac{I n v_{i}}{\left(1+R_{I} \times I\right)^{i}}
\end{gathered}
$$

Посредством выделенных рисковых коэффициентов формула (4) может быть преобразована в:

$$
\begin{gathered}
\text { чдД }=\sum_{i=1}^{n}\left(1-I T_{i}\right) \times\left(\frac{\left(1-R C_{2}\right) \times\left(1-R C_{3}\right) \times P_{i} \times Q_{i}}{\left(1+\left(1+R C_{1}\right) \times I\right)^{i}}-\right. \\
-\frac{\left.\left(1-R C_{4}\right) \times V C_{i}+\left(1-R C_{5}\right) \times F C_{i}+\left(1-R C_{6}\right) M P_{i}\right)}{\left(1+\left(1+R C_{1}\right) \times I\right)^{i}}-, \\
\left.-\frac{\left(1-R C_{7}\right) O E_{i}}{\left(1+\left(1+R C_{1}\right) \times I\right)^{i}}\right)-\sum_{i=1}^{n} \frac{I n v_{i}}{\left(1+\left(1+R C_{1}\right) \times I\right)^{i}}
\end{gathered}
$$

где $R C_{1}$ - коэффициент риска повышения стоимости капитала $I$;

$R C_{2}$ - коэффициент риска уменьшения цены единицы продукции $P_{i}$;

$R C_{3}$ - коэффициент риска снижения объема продаж $Q_{i}$;

$R C_{4}$ - коэффициент риска роста переменных издержек в себестоимости продукции $V C_{i}$;

$R C_{5}$ - коэффициент риска увеличения постоянных издержек в себестоимости продукции $F C_{i}$;

$R C_{6}$ - коэффициент риска роста долговой нагрузки в рамках обслуживания кредита $M P_{i}$ (в случае ее наличия);

$R C_{7}$ - коэффициент риска увеличения прочих расходов, относимых на финансовый результат организации, $O E_{i}$.

Привлечение инжиниринговой компании обеспечивает снижение воздействия рассмотренных рисков. Это обеспечивается ее высокой компетентностью, наличием значительного опыта практической деятельности, обладанием массивом систематизированных данных о возможных рисках, уровнем их негативного воздействия на производственный процесс и потенциальными способами предотвращения, минимизации. В данном случае формируется реинжиниринговый консоль, обусловленный снижением рисков.

3. Разработка реинжиниринговых решений. Инжиниринговая компания, опираясь на свой опыт и компетенции, имеет возможность выбора оптимальных подходов при оценке технологических решений, оборудования, программного обеспечения с позиций реализиции заданного качества при минимизации издержек. В конечном итоге рост стоимости единицы продукции и объема продаж в натуральном выражении сопровождается уменьшением себестоимости в части переменных издержек, уменьшением объема требуемых инвестиций.

Включение в формулу (3) коэффициента влияния разработки реинжиниринговых решений $C_{g}$ дает возможность представить общее влияние на размер ЧДД следующим образом: 


$$
\begin{gathered}
\text { ЧдД }=\sum_{i=1}^{n}\left(1-I T_{i}\right) \times\left(\frac{\left(1+C_{g}\right) \times P \times_{i} Q_{i}-\left(1-C_{g}\right) \times V C_{i}-F C_{i}}{(1+I)^{i}}-\right. \\
\left.-\frac{M P_{i}+O E_{i}}{(1+I)^{i}}\right)-\sum_{i=1}^{n} \frac{\left(1-C_{g}\right) I n v_{i}}{(1+I)^{i}}
\end{gathered}
$$

Здесь формируется реинжиниринговый консоль, обусловленный разработкой реинжиниринговых решений.

4. Высокий уровень деловой репутации инжиниринговой компании, транслируемый организации-заказчику. Инжиниринговая компания, обладая высоким уровнем деловой репутации и отлаженными деловыми связями, имеет возможность обеспечить снижение стоимости финансирования реинжинирингового проекта, в результате чего достигается снижение долгового бремени на организацию ЖКХ. Подставив в формулу (3) коэффициент имиджа инжиниринговой компании $C_{i m g}$, определим величину влияния на ЧДД репутационных преимуществ инжиниринговой компании:

$$
\text { чДД }=\sum_{i=1}^{n} \frac{\left(1-I T_{i}\right) \times\left(P_{i} \times Q_{i}-V C_{i}-F C_{i}-\left(1-C_{i m g}\right) \times M P_{i}-O E_{i}\right)}{\left(1+\left(1-C_{i m g}\right) \times I\right)^{i}}-
$$

Здесь обнаруживает себя реинжиниринговый консоль, обусловленный высоким уровнем деловой репутации инжиниринговой компании.

Совокупное влияние, оказываемое на чистый дисконтированный доход проекта четырьмя преимуществами привлечения в его реализацию инжиниринговой компании, можно представить следующим образом

$$
\begin{gathered}
\text { чДД }=\sum_{i=1}^{n}\left(1-I T_{i}\right) \times\left(\frac{\left(1+C_{g}\right) \times\left(1-R C_{2}\right) \times\left(1-R C_{3}\right) \times P_{i} \times Q_{i}}{\left(1+\left(1-C_{i m g}\right) \times\left(1+R C_{1}\right) \times I\right)^{i}}-\right. \\
-\frac{\left(1-C_{g}\right) \times\left(1-R C_{4}\right) \times V C_{i}+\left(1+R C_{5}\right) \times F C_{i}}{\left(1+\left(1-C_{i m g}\right) \times\left(1+R C_{1}\right) \times I\right)^{i}}- \\
\left.-\frac{\left(1-C_{i m g}\right) \times\left(1+R C_{6}\right) \times M P_{i}+\left(1+R C_{7}\right) \times O E_{i}}{\left(1+\left(1-C_{i m g}\right) \times\left(1+R C_{1}\right) \times I\right)^{i}}\right)- \\
-\sum_{i=1}^{n} \frac{\left(1-C_{g}\right) I n v_{i}}{\left(1+\left(1+R C_{1}\right) I\right)^{i}}
\end{gathered}
$$

Мы приняли, что величина реинжинирингового консоля определяется как чистый дисконтированный доход проекта, который предусматривает применение услуг инжиниринговой компании (ЧДД ного дохода проекта без ее привлечения (ЧДДо). Поскольку величина ЧДДо неизменна, для максимизации реинжинирингового консоля необходимо максимизировать значение ЧДД 
P. Р. Мавлютов. Оценка обоснованности перепланирования ключевых производственных процессов организаций в сфере жилищно-коммунального хозяйства

$$
\begin{aligned}
& \text { чдД } \\
& R E C=\sum_{i=1}^{n}\left(1-I T_{i}\right) \times\left(\frac{\left(1+C_{g}\right) \times\left(1-R C_{2}\right) \times\left(1-R C_{3}\right) \times P_{i} \times Q_{i}}{\left(1+\left(1-C_{i m g}\right) \times\left(1+R C_{1}\right) \times I\right)^{i}}-\right. \\
&-\frac{\left(1-C_{g}\right) \times\left(1-R C_{4}\right) \times V C_{i}+\left(1+R C_{5}\right) \times F C_{i}}{\left(1+\left(1-C_{i m g}\right) \times\left(1+R C_{1}\right) \times I\right)^{i}}- \\
&\left.-\frac{\left(1-C_{i m g}\right) \times\left(1+R C_{6}\right) \times M P_{i}+\left(1+R C_{7}\right) \times O E_{i}}{\left(1+\left(1-C_{i m g}\right) \times\left(1+R C_{1}\right) \times I\right)^{i}}\right)- \\
&-\sum_{i=1}^{n} \frac{\left(1-C_{g}\right) I n v_{i}}{\left(1+\left(1+R C_{1}\right) I\right)^{i}} \rightarrow \max
\end{aligned}
$$

при выполнении ограничения: $0 \leq i \leq n$.

Для российских организаций сферы ЖКХ в стратегическом плане востребован реинжиниринг производственных процессов, под которым нами понимается радикальное перепланирование ключевых производственных процессов в целях качественного улучшения их выполнения с точки зрения затрат, качества обслуживания и скорости. Для организации вне зависимости от размера издержек, вызванных использованием услуг инжиниринговой компании, в современных условиях новой технологической революции формируется положительный эффект, который обозначен нами как реинжиниринговый консоль. Предложенный нами подход к определению величины реинжинирингового консоля учитывает четыре преимущества, достигаемых организацией ЖКХ привлечением инжиниринговой компании: сокращение срока реализации проекта; частичное нивелирование рисков; разработка реинжиниринговых решений; высокий уровень деловой репутации инжиниринговой компании, транслируемый компании-заказчику. Авторский подход применим при разработке управленческих решений организациями сферы ЖКХ как в России, так и в других странах, характеризующихся схожими условиями ведения хозяйственной деятельности. Наряду с этим инжиниринговые компании могут применять в своей практике предложенный подход как инструмент продвижения своих услуг.

\section{Литература}

1. Betts M., Wood-Harper. Re-engineering Construction: a New Management Research Agenda // Construction Management and Economics. 1994. № 12. P. 551-556.

2. Chikofsky E., Cross J. Reverse Engineering and Design Recovery: a Taxonomy. IEEE Software, 1990. P. 13-18.

3. Dorf R. C. The Engineering Handbook. CRC Press, 2000. 2976 p.

4. Business Process Reengineering. Breakpoint Strategies for Market Dominance / H. J. Johansson, P. McHugh, A. J. Pendlebury, W. A. Wheeler. Wiley, New York, 1993.

5. Баринов В., Магомедова Ю. Реформирование системы управления крупной инжиниринговой компанией при подготовке к новому проекту // Проблемы теории и практики управления. 2010. № 10. С. 62-72. Текст: непосредственный.

6. Новая технологическая революция: вызовы и возможности для России / Г. И. Идрисов, В. Н. Княгинин, А. Л. Кудрин, Е. С. Рожкова // Вопросы экономики. 2018. № 4. С. 5-25. Текст: непосредственный.

7. Лифанов И. Д., Шинкевич А. И. Специфика и перспективы развития инжиниринговых услуг в инновационной сфере // Российское предпринимательство. 2014. № 19. С. 16-27. Текст: непосредственный. 
8. Мавлютов Р. Р. К вопросу оценки потенциала повышения эффективности управления в организациях жилищной сферы // Вестник Бурятского государственного университета. Экономика и менеджмент. 2020. № 4. С. 102-110. Текст: непосредственный.

9. Мавлютов Р. Р., Тихонова Т. А. Оценка экономической обоснованности реализации проектов энергосбережения в бюджетной сфере // Финансовая экономика. 2018. № 6. С. 844-846. Текст: непосредственный.

10. Метелева М. А. Оценка качества управления инвестиционными прочесами в регионе на основе эконометрического моделирования // Вестник Бурятского государственного университета. Экономика и менеджмент. 2017. № 3. С. 26-33. Текст: непосредственный.

Статья поступила в редакцию 18.02.2021; одобрена после рецензирования 28.04.2021; принята к публикации 28.04.2021.

\section{ASSESSMENT OF THE REASONABLENESS OF REPLANNING KEY PRODUCTION PROCESSES OF HOUSING AND UTILITIES ORGANIZATIONS}

Ramil R. Mavlyutov

Cand. Sci. (Econ.), A/Prof.,

Volgograd State Technical University

28 Prospect imeni Lenina, Volgograd 400005, Russia

ramil-2002@mail.ru

Abstract. Today the primary problem of domestic organizations in the sphere of housing and utilities is the introduction of advanced technological solutions. A new paradigm aimed at joining the global processes of technological revolution is being developed in Russia in the context of the declared goal of widespread introduction of advanced digital and engineering solutions in urban and communal infrastructure, which is implemented within the framework of the national project "Housing and Urban Environment" and the national program "Digital Economy". This cannot be achieved without a radical replanning of key production processes in housing and utilities organizations. We regard this procedure as "reengineering of production processes". The article presents an approach to assessing the feasibility of production processes reengineering in housing and utility sector with the assistance of an engineering company. We have emphasized the benefits of engineering company involvement. The proposed approach makes it possible to calculate the reengineering consol, which allows an organization and an engineering company to make a reasoned decision on the implementation of a reengineering project. This research can be of interest for both potential participants of the process and for researchers in this field.

Keywords: housing and utilities infrastructure, organization, technological revolution, production process, reengineering, assessment, housing stock, communal infrastructure, net present value, risk

For citation

Mavlyutov R. R. Assessment of the Reasonableness of Replanning Key Production Processes of Housing and Utilities Organizations. Bulletin of Buryat State University. Economy and Management. 2021; 2: 24-32 (In Russ.).

The article was submitted 18.02.2021; approved after reviewing 28.04.2021; accepted for publication 28.04.2021. 